\title{
The association between self-reported grocery store access, fruit and vegetable intake, sugar-sweetened beverage consumption, and obesity in a racially diverse, low-income population
}

\author{
Lauren Nichol Gase ${ }^{1}{ }^{*}$, Amelia Rose DeFosset ${ }^{1}$, Lisa V. Smith ${ }^{2}$ and Tony Kuo ${ }^{1,3,4}$ \\ 1 Division of Chronic Disease and Injury Prevention, Los Angeles County Department of Public Health, Los Angeles, CA, USA \\ ${ }^{2}$ Office of Health Assessment and Epidemiology, Los Angeles County Department of Public Health, Los Angeles, CA, USA \\ ${ }^{3}$ Department of Family Medicine, David Geffen School of Medicine at the University of California Los Angeles, Los Angeles, CA, USA \\ ${ }^{4}$ Department of Epidemiology, Los Angeles Fielding School of Public Health, University of California Los Angeles, Los Angeles, CA, USA
}

\author{
Edited by: \\ André F. S. Amaral, Imperial College \\ London, UK \\ Reviewed by: \\ Arthur Eumann Mesas, Universidade \\ Estadual de Londrina, Brazil \\ Xiaoguang Ma, University of South \\ Carolina, USA \\ *Correspondence: \\ Lauren Nichol Gase, Division of \\ Chronic Disease and Injury \\ Prevention, Los Angeles County \\ Department of Public Health, 3530 \\ Wilshire Blvd, 8th Floor, Los Angeles, \\ CA 90010, USA \\ e-mail: Igase@ph.lacounty.gov
}

This study sought to examine the relationship between self-reported time and distance to the nearest retail grocery store, healthy and unhealthy food consumption, and objectively measured body mass index (BMI). We conducted a survey with 1,503 racially diverse, lowincome residents at five public health centers in Los Angeles County. Most participants reported shopping at a supermarket $(86.7 \%)$ and driving $(59.9 \%)$ to their usual source for groceries. Over half reported living less than a mile from (58.9\%) and traveling $5 \mathrm{~min}$ or less to reach $(50.3 \%)$ the nearest grocery store. In the multivariable regression models, neither self-reported distance nor time to the nearest grocery store was consistently associated with fruit and vegetable intake, sugar-sweetened beverage consumption, or BMI. Results suggest that the need to consider access and quality as well as urban planning and transportation, when examining the relationship between the retail food environment and health outcomes.

Keywords: obesity, food dessert, fruit and vegetable consumption, food access, food environment

\section{INTRODUCTION}

Poor diet is associated with a variety of health problems, including obesity, cardiovascular disease, hypertension, diabetes, osteoporosis, and some forms of cancer (1). In 2011-2012, more than one-third of all adults were classified as obese in the U.S. (2). Obesity rates are higher among African-Americans $(47.8 \%)$ and Hispanics (42.5\%) than in whites (32.6\%) and Asians (10.8\%) (2). Estimates suggest that obesity is responsible for $\$ 147$ billion in annual medical costs (3).

Healthy eating is a complex phenomenon, influenced by a variety of interacting environmental, social, and individual factors $(4,5)$. For example, environmental effects can be moderated or mediated by demographic, psychosocial, or perceived environment variables (4). While the concept of "food environment" includes multiple dimensions (e.g., access, availability, price, and promotion) and settings (e.g., homes, restaurants, worksites, and recreational facilities), retail food stores are thought to be important contributors to eating patterns because of the frequency and volume at which people purchase food at such locations $(4,6)$. Among retail stores, supermarkets have been shown to offer the greatest variety of food at the lowest cost $(7,8)$. In recent years, increased attention has been placed on eliminating the so called "food desert" areas (6). The United States Department of Agriculture (USDA) defines food deserts as existing in communities that are (a) low-income, based on having a poverty rate of $20 \%$ or greater or a median family income at or below $80 \%$ of the area median family income and (b) low-access, based on the determination that at least 500 individuals or at least $33 \%$ of the census tract's population live more than 1 mile from a supermarket or large grocery store (10 miles, in non-metropolitan census tracts) (9).

Despite the increased attention and funding to eliminate food deserts, much remains unknown about their influence on healthy eating and obesity. Several studies have found associations between access to supermarkets and healthier diets (4). For instance, one study documented a $32 \%$ increase in fruit and vegetable consumption among African-American residents per additional supermarket in their census tract (10). However, in a systematic review, few studies found an association between access to supermarkets and fruit and vegetable consumption, although access to supermarkets was associated with lower weight status (11). These null findings are echoed by a number of recent studies $(12,13)$. For example, studies that have considered price, in addition to proximity, found no association between distance to grocery stores and diet or body mass index (BMI) $(14,15)$. Notably, at least one study found a negative effect, wherein greater access to grocery stores was associated with higher BMI in women (16).

The purpose of this study was to examine the relationship between self-reported food environment, healthy eating habits, and obesity. The study assessed data on food-purchasing patterns, proximity to food outlets, healthy and unhealthy food consumption, and obesity in a sample of low-income Los Angeles County residents. This study adds to the literature by assessing both self-reported time and distance to the nearest grocery store and 
examines the association between grocery store access with both dietary and anthropometric outcomes.

\section{MATERIALS AND METHODS \\ SAMPLE}

We analyzed data from the second round of the Los Angeles County Health and Nutrition Examination Survey (LA HANES) conducted during February through April of 2012. The LA HANES was a community health assessment project, which described the health profiles of a sample of low-income community-dwelling adults who utilized multi-purpose public health centers in the region. Health centers operated by the Los Angeles County Department of Public Health typically provide a range of services, including immunizations, treatment of tuberculosis and sexually transmitted diseases, and outreach programs for the surrounding communities. Five health centers were randomly selected from among the pool of centers $(n=7)$ in a pre-defined geographic areas that served a high volume of low-income clients and were the focus area for an array of obesity prevention interventions implemented by several recent federal initiatives such as the Communities Putting Prevention to Work program, the Community Transformation Grants, and the Nutrition, Education, and Obesity Prevention Project. The referent profile of these health centers is illustrated by a 2012 survey of clinic visitors, which showed that health center clients were mostly Hispanic (40\%) or AfricanAmerican (22\%); uninsured (62\%); a number of them unemployed (42\%); and nearly half with an annual household income of $<\$ 20,000$.

\section{STUDY PROTOCOL}

To recruit and enroll participants in LA HANES, trained recruiters approached all individuals waiting for services in the clinic waiting areas to screen them for interest and eligibility. To be eligible, participants had to be (a) age 18 years or older, (b) seeking services at the clinic on the recruitment day, (c) residents of LAC, (d) able to complete surveys in English or Spanish, and (d) not currently pregnant. If an individual was eligible and interested in participating, he/she was scheduled for an appointment.

All participants were asked to return on a Saturday to a designated survey site (i.e., one of five health centers) and completed the full assessment that day including a 95-item questionnaire, which collected information on demographics, tobacco use, and second hand smoke exposure, chronic conditions, sexual health, diet, and physical activity. Trained LA HANES clinical staff collected anthropometric and clinical measures, including height (inches), weight (pounds), and blood pressure. On average, each survey appointment lasted $45 \mathrm{~min}$ and each participant was compensated with a $\$ 50$ Visa gift card for his/her time. The study was approved by the Los Angeles County Department of Public Health Institutional Review Board. The study conformed to all ethical standards, including obtaining written consent from all participants prior to enrollment.

\section{MEASURES}

Weight status

Participant height and weight were each measured two times using a wall-mounted stadiometer (Seca 213) and a digital scale (Seca
876), respectively. These measurements were averaged and used to calculate BMI using the formula - weight (lbs)/[height (inches)] $2 \times 703$. BMI was treated as a continuous outcome as well as a categorical outcome, with categories determined according to the World Health Organization criteria, classifying participants as underweight/normal $(<24.9)$, overweight (between 25.0 and $29.9)$, or obese $(\geq 30.0)$.

\section{Healthy eating}

Healthy eating was operationalized two ways: (a) fruit and vegetable intake and (b) sugar-sweetened beverage consumption. First, participants were asked to respond to six items about their frequency of eating fruits and vegetables for morning meal/snack, lunchtime/afternoon snack, and suppertime/evening snack for the past 7 days. Participant responses for each of the six items were recoded to correspond to the average number of fruits and vegetables eaten per day - 0 (never), 0.286 (1-3 times per week), 0.714 (4-6 times per week), 1 ( 1 time per day), 2 (2 times per day), 3 (3 times per day), or 4 ( 4 times per day) - and summed, using scoring criteria defined by the National Cancer Institute (17). Fruit and vegetable intake was used as both a continuous outcome and a categorical outcome, by classifying participants as eating $\geq 5$ servings or $<5$ servings per day.

To measure sugar-sweetened beverage (SSB) consumption, participants were asked to report intake of a can, bottle, or glass of (a) soda or pop, (b) sports drinks, (c) energy drinks, and (d) other sugar-sweetened beverages (e.g., lemonade, sweetened tea). Participant responses for each of the 4 items were coded as 0 (never), 2 (1-3 times), 5 (4-6 times), 7 (1 time per day), 14 (2 times per day), 21 (3 times per day), or 28 (4 times per day) and summed to obtain a measure of the average number of SSBs consumed per week (18). Responses were also transformed into a categorical variable, based on whether participants consumed SSBs never (0), weekly (1-6), or daily ( $\geq 7)$.

\section{Self-reported food environment}

To assess shopping patterns, participants were asked "Where do you usually shop for groceries?" Response options included supermarket, corner store, farmer's market, or other. When stores listed as "other" could be classified into the existing categories, they were recoded. Participants were asked how they usually get from their home to the nearest grocery store. Response options included drive alone, carpool, bus, metro, motorcycle, bicycle, or other. Response options were coded as drive (drive alone, motorcycle, or carpool), public transportation (bus or metro), bicycle/skateboard, walk, or multiple modes (if participants selected $>1$ response option).

To assess distance from the nearest grocery store, participants were asked to report: (a) how many minutes it usually takes for them to get to the nearest grocery store and (b) how many miles it is from their home to the nearest grocery store (one-way). Variables were treated both as continuous and categorical predictors. Minutes to the grocery store were categorized as $\geq 5,6-10,11-20$, $<20 \mathrm{~min}$ according to the distribution of responses. Distance to the grocery store was categorized as more or $<1$ mile, according to the "low-access" criteria proposed by the USDA, as well as more or less than 0.5 miles, according to generally accepted distances for walking nationally and internationally (6). 


\section{Control variables}

Participants were asked to provide their age (as a continuous variable), gender (male or female), education level (completed less than high school, high-school graduate/GED, some college, or college graduate/professional degree), and race/ethnicity (AfricanAmerican, Hispanic, white, Asian, Native American, or multiethnic). Because of the small number of Asians, Native Americans, and those who identified themselves as multiethnic, these race categories were combined into an "other" category.

\section{DATA ANALYSIS}

Bivariate analyses were conducted to examine the relationship between time to nearest grocery store and (a) mode of transportation used and (b) type of store most frequently shopped at. Multivariable regression analyses were conducted to examine the association between self-reported food environment and diet/obesity. The impact of self-reported food environment was tested using (a) reported distance to grocery stores (as a continuous and categorical variable) and (b) reported time to the nearest grocery store (as a continuous and categorical variable). Outcomes included fruit and vegetable intake, SSB consumption, and BMI. Linear regression was conducted to examine the relationship between food environments and continuous normally distributed outcomes (BMI) and negative binomial regression was conducted for count data variables that displayed a skewed distribution (fruit and vegetable intake and SSB intake) to allow for over-dispersion (19). Negative binomial modeling was used instead of log-transformed linear regression in order to model the dispersion and prevent loss of data (19). Negative binomial regression coefficients were exponentiated to produce rate ratios (vegetables consumed per day), in accordance with standard practices for analysis of cross-sectional count data (19).

To test the robustness of the model, analyses were also conducted using categorical versions of the outcome variables, including logistic regression for whether participants who reported eating $\geq 5$ servings of fruit and vegetables a day and an ordered logistic regression for categories of SSB consumption and BMI. In addition, stratified versions of all multivariable models were constructed to examine differences in the relationship between distance/time to the nearest grocery store and each of the outcomes, by travel mode [drive, public transportation, active transportation (walk, bicycle, or skateboard), or multiple modes].

Case wise deletion was conducted so that all descriptive and multivariable analyses were performed using the sub-set of cases that included no missing data on any of the variables included in the analyses. To examine the impact of missing data, all models were also performed after conducting multiple imputations of missing data with predictive mean matching, using 20 replicates. All multivariable models included demographic control variables (age, gender, race/ethnicity, and education level). Consideration was given to including other potential variables that could confound the relationship between the predictors and the outcomes (e.g., physical activity, employment status, U.S. versus foreign born, other health behaviors). However, the robust null results of multivariable and stratified analyses suggested that further analyses of these confounders were not needed. Because of the use of multiple models, parameter estimates were judged to be significant if the two-tailed $p$-value was $<0.01$. All analyses were performed using the Stata statistical computing software, version 13.0 (StataCorp LP, College Station, TX, USA).

\section{RESULTS}

In total, 3,317 people were approached in the health centers: 2,184 were eligible and made appointments. Of the 2,184 people invited to participate, 1,503 completed the survey, for a response rate of $69 \%$. Case wise deletion yielded a sample of 1,318 participants.

A majority of the participants were either African-American or Latino. About a quarter reported having a college degree $(23.5 \%)$, while roughly a third reported being currently employed full or part time $(37.3 \%)$. Most reported being between the ages of 25 and 44 , but ages ranged from 18 to 84 (Table 1). Analysis of participant zip codes suggested that the sample included individuals from a wide geographic range in Los Angeles County.

Most participants $(86.7 \%)$ reported shopping at a supermarket as their usual source for groceries. Very few reported a corner store or a farmer's market. The most frequently reported travel modes to the store included car (59.9\%), walking (18.1\%), and public transportation (10.8\%). The mean distance to the nearest grocery store was 2.5 miles $(S D=4.1)$. The median distance was 1 mile, with $42.1 \%$ of people reporting living more than a mile from the nearest grocery store and $75.9 \%$ of people living more than 0.5 miles. The mean travel time to reach the nearest grocery store was $10.2 \mathrm{~min}(\mathrm{SD}=10.6)$. The median travel time was $5 \mathrm{~min}$. While travel times ranged from 0 to $120 \mathrm{~min}$, most reported traveling $5 \mathrm{~min}$ or less $(50.3 \%)$ or $6-10 \mathrm{~min}(26.8 \%)$.

The average number of fruits and vegetables consumed per day was $3.8(\mathrm{SD}=4.6)$. The median number was 2.1 and most people $(77 \%)$ ate fewer than five fruits and vegetables per day. The average number of SSBs consumed per week was $14.8(\mathrm{SD}=18.3)$. The median number consumed was 8 . Over half (57.4\%) reported consuming at least one SSB per day, while $32.1 \%$ reported weekly consumption, and $10 \%$ reported never consuming them. Mean BMI was $28.6(\mathrm{SD}=7.1)$ and ranged from 17.9 to 50.5 . About one-third $(34.5 \%)$ of participants was classified as obese, a third $(31.1 \%)$ was classified as overweight, and the final third $(34.4 \%)$ was classified as having normal weight.

Distance and time to the grocery store were moderately correlated $(\rho=0.3209)$. Time spent traveling to the grocery store differed significantly by mode of travel ( $p<0.00001)$, with public transportation being associated with the longest travel time, and car being associated with the shortest. Time spent traveling to the grocery store did not significantly differ by the usual type of store accessed ( $p=0.1257$ ) (Table 2 ).

In the multivariable models, neither distance nor time to the nearest grocery store was significantly associated with fruit and vegetable intake, SSB consumption, or BMI. Many of the control variables were significantly associated with the outcomes across models (Table 3). Use of categorical predictors and outcomes did not substantively change the results.

Stratified analysis showed some similar trends across models. Consistently, among those who reported driving to the store, greater time and distance from the store was associated with 
Table 1 | Participant characteristics, round two of the Los Angeles County Health and Nutrition Examination Survey, $2012(N=1,318)^{\mathrm{a}}$.

\begin{tabular}{|c|c|}
\hline & $\begin{array}{l}\text { Number (\%) or } \\
\text { mean (SD) }\end{array}$ \\
\hline \multicolumn{2}{|l|}{ Demographics } \\
\hline \multicolumn{2}{|l|}{ Gender } \\
\hline Female & $686(52.1 \%)$ \\
\hline Male & $632(48.0 \%)$ \\
\hline \multicolumn{2}{|l|}{ Race/ethnicity } \\
\hline African-American & $649(49.2 \%)$ \\
\hline Latino & $351(26.6 \%)$ \\
\hline White & $167(12.7 \%)$ \\
\hline Other & $151(11.5 \%)$ \\
\hline \multicolumn{2}{|l|}{ Education } \\
\hline Less than high school & $204(15.5 \%)$ \\
\hline High-school graduate & $295(22.4 \%)$ \\
\hline Some college & $510(38.7 \%)$ \\
\hline College graduate & $238(18.1 \%)$ \\
\hline Postgraduate/professional degree & $71(5.4 \%)$ \\
\hline \multicolumn{2}{|l|}{ Employment } \\
\hline Employed (full or part time) & $492(37.3 \%)$ \\
\hline Born in the United States & $967(73.5 \%)$ \\
\hline Age (years) & $35.6(12.5)$ \\
\hline \multicolumn{2}{|l|}{ Shopping patterns and food access } \\
\hline \multicolumn{2}{|l|}{ Usual grocery source } \\
\hline Supermarket & $1142(86.7 \%)$ \\
\hline Corner store & $42(3.2 \%)$ \\
\hline Farmer's market & $36(2.7 \%)$ \\
\hline Multiple places & $93(7.1 \%)$ \\
\hline Other & $5(0.4 \%)$ \\
\hline \multicolumn{2}{|l|}{ Usual travel mode to grocery store } \\
\hline Car & 789 (59.9\%) \\
\hline Public transportation & $142(10.8 \%)$ \\
\hline Walk & $238(18.1 \%)$ \\
\hline Bicycle/skateboard & $23(1.8 \%)$ \\
\hline Multiple modes & $126(9.6 \%)$ \\
\hline Miles from home to nearest grocery store & $2.5(4.1)$ \\
\hline Travel time to nearest grocery store (minutes) & $10.2(10.6)$ \\
\hline \multicolumn{2}{|l|}{ Eating patterns and body mass index } \\
\hline Number of fruits and vegetable eaten (per day) & $3.8(4.6)$ \\
\hline $\begin{array}{l}\text { Number of sugar-sweetened beverage } \\
\text { consumed (per week) }\end{array}$ & $14.8(18.3)$ \\
\hline Body mass index (pounds/inches ${ }^{2}$ ) & $28.6(7.1)$ \\
\hline
\end{tabular}

${ }^{a}$ Participants who reported no missing data on any of the variables were included in the bivariate analyses.

eating more fruits and vegetables, for example, the rate ratio of the negative binominal regression model of time on total fruit and vegetable consumption $(\mathrm{IRR}=1.008,95 \% \mathrm{CI}=1.001,1.015)$, approaching statistical significance $(p=0.04)$. Among those who used active transportation, greater time and distance from the store was associated with greater BMI, for example, the odds of being obese were 1.066 times as great $(95 \% \mathrm{CI}=1.020,1.116)$ for each additional minute individuals lived from the store $(p=0.005)$, after controlling for other factors in the model.
Table 2 | Relationship between self-reported travel time to the nearest grocery store, travel mode, and usual grocery source among LA HANES participants, $2012(N=1,318)^{\mathrm{a}}$.

$\begin{array}{ll}\text { Travel time to nearest } & \text { ANOVA } \\ \text { grocery store (in minutes) } & p \text {-value } \\ \text { Mean (SD) } & \end{array}$

\begin{tabular}{lcc}
\hline Travel mode & & \\
Car & $8.4(9.1)$ & $<0.00001$ \\
Public transportation & $20.1(15.0)$ & \\
Walk & $9.6(8.0)$ & \\
Bicycle/skateboard & $11.2(8.6)$ & \\
Multiple modes & $11.3(11.1)$ & 0.1257 \\
Usual grocery source & & \\
Supermarket & $9.9(10.3)$ & \\
Corner store & $10.4(6.7)$ & \\
Farmers market & $13.0(10.0)$ & \\
Other & $16(13.9)$ & \\
Multiple places & $11.9(14.4)$ &
\end{tabular}

${ }^{a}$ Participants who reported no missing data on any of the variables were included in the analyses.

\section{DISCUSSION}

Neither distance nor time to the nearest grocery store was significantly associated with fruit and vegetable intake, SSB consumption, or BMI across models. The results were robust to the specification of the model, including the use of continuous or categorical independent and dependent variables and stratified analysis. Previous literature has found mixed results on the association between elements of the food environment, eating behaviors, and health outcomes (11). The present study findings align with studies, which failed to find significant associations between distance to food outlets and dietary intake and BMI $(12,20)$.

There are many potential reasons for the null findings. First, Los Angeles County is considered to be a car-centric jurisdiction. In our sample, a majority of participants, even though they were low-income, reported using a car to get to the grocery store. This percentage is larger than those reported by other studies that have assessed travel mode to usual food source among similar populations (21). The increased reliance on car travel to access grocery outlets may lessen the importance of physical distance in determining food purchasing and consumption patterns (12). Although not consistent, results of our stratified analyses suggest that greater time and distance from the grocery store was associated with higher BMI among those who walked or biked to the store. There is support in the literature for this notion. The mitigating effects of car ownership have been observed in research examining the association between health outcomes and fast food density, wherein concentration of fast food restaurants was associated with higher BMI only in residents who lacked access to a car (22).

Second, access to grocery stores is frequently associated with increased access to food outlets generally, including fast food restaurants. In a recent study by Hattori and colleagues (12), lowincome individuals were found to have greater access to all types 
Table 3 | Multivariable regression models of the relationship between self-reported access to the grocery store and fruit and vegetable intake, sugar-sweetened beverage consumption, and body mass index among LA HANES participants, $2012(N=1,318)^{\mathrm{a}}$

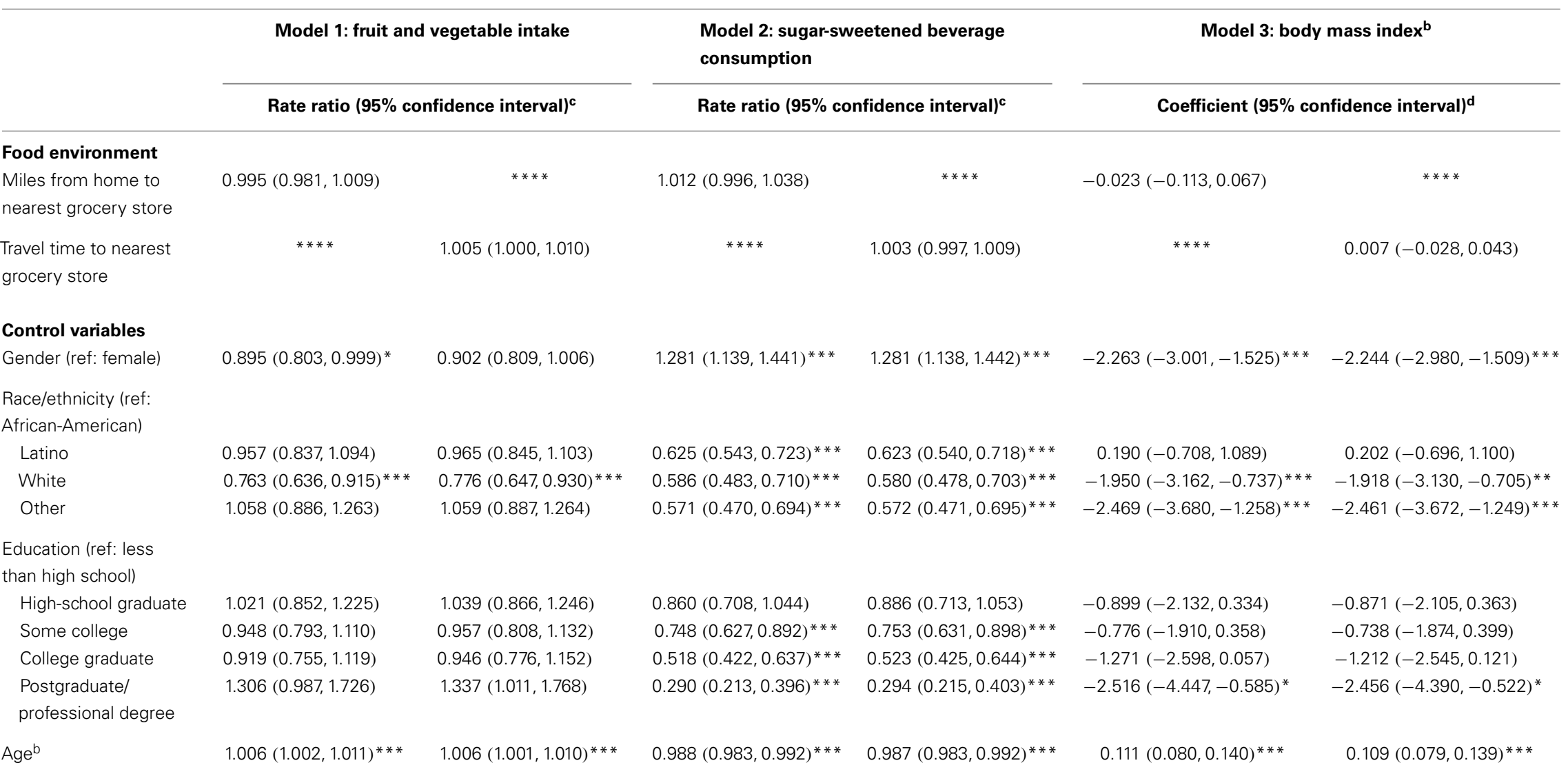

a Participants who reported no missing data on any of the variables were included in the multivariable analyses.

${ }^{b}$ Continuous variable.

${ }^{c}$ Negative binomial regression model.

¿Linear regression model.

**** Covariate was excluded from the model.

${ }^{*} p<0.05,{ }^{* *} p<0.01,{ }^{* *} p<0.001$. 
of food outlets, as compared to their more affluent counterparts. Thus, disadvantaged communities have been described as "food swamps" - that is, they often contain a plethora of retail food establishments that sell unhealthy foods (23). Given these associations, the indicator "distance from the grocery store" may serve as a proxy for measuring general food access that also reflects the density of retail food venues that sell unhealthy products.

Results of this study support the need for a multi-dimensional approach when studying the relationship between food stores and health outcomes. In general, few studies have examined multiple dimensions of access simultaneously (24), such as within-store availability of healthy food (20), variety of retail options (25), or affordability, quality, and cultural acceptability in addition to proximity (26). As all of these factors are likely to impact consumption patterns, a more comprehensive approach to study the relationship between food environments and eating behaviors should measure access as well as factors related to food quality, price, and promotional environment. At minimum, indices that consider the presence of healthy and unhealthy foods outlets (27-29) would provide a more holistic appraisal of the settings in which people make food choices.

Looking beyond the use of cross-sectional data, for example, quasi-experimental designs should be considered to examine how the retail food environment affects diet and health. Several such studies have been conducted in the United Kingdom, with mixed results $(30,31)$. In the U.S., growing political momentum has enabled many full-service grocery stores to open in disadvantaged neighborhoods, providing an opportunity to further study environmental factors that can influence food access and food selection. Capitalizing on such momentum, future studies can help elucidate how changes in the immediate food environment may differentially affect the diet of underserved populations.

\section{LIMITATIONS}

The present study provides insights on the association between self-reported food environment, fruit and vegetable intake, sugar-sweetened beverage consumption, and obesity. Despite its strengths, the study has a number of limitations. First, we relied on self-reported measures of time and distance to the nearest grocery store. While these measures provide an important perspective on access, the extent to which participants' subjective categorization of retail outlets and distance represents a valid measure of food access is unclear. While over half of the people in the sample reported living more than a mile from the nearest grocery store, many may not live in a true "food desert." According the USDA, very few census tracts in Los Angeles County meet the two criteria for living in a food desert (9). Our measures may not have been sensitive enough to identify people for whom food access is a true problem. Also, we asked people to identify the grocery store nearest to their home, which may not be the store at which they usually shop. Second, because the data were collected in public health centers, survey participants may have tended to over-report fruit and vegetable consumption and underreport SSB consumption as a result of social desirability bias. Additionally, the less than perfect response rate may have resulted in selection bias. Third, only two dimensions of healthy eating were assessed in the study: fruit and vegetable intake and sugar-sweetened beverage consumption.
Lastly, because the study sample was not a true random sample of all LAC residents, the findings may not be generalizable to the general adult population in the region. None-the-less, the sample does represent the low-income segment of the LAC population that was targeted by recent obesity prevention efforts in the jurisdiction.

\section{CONCLUSION}

Study findings failed to demonstrate a significant association between access to grocery stores, fruit and vegetable intake, sugarsweetened beverage consumption, and obesity, suggesting that improving access to grocery stores as a standalone strategy to research and intervene against the obesity epidemic may not be sufficient. However, to misinterpret this null finding and discount the utility of the approach would be misleading. Rather, the results of the study, along with previous work, suggest that changing eating behaviors may require a multi-dimensional approach to conceptualizing the food environment. Such an approach could lead to more discernable impacts by considering the complexity of food environments and including synergistic measures and strategies that increase access to healthy, affordable options in multiple venues as well as educate and empower residents of these low-income communities to eat more healthfully.

\section{AUTHOR CONTRIBUTIONS}

Lauren Nichol Gase developed the conceptual framework for the analysis and led the data analysis. She drafted the primary text of the manuscript. Amelia Rose DeFosset provided technical assistance, including background research, consultation, and text revision. Lisa V. Smith led LA HANES data collection and provided technical assistance for data analysis. Tony Kuo designed the original LA HANES study; he consulted on the analysis plan and manuscript development. All authors have reviewed and approved the final version of the article.

\section{ACKNOWLEDGMENTS}

The authors thank the staff in the Office of Health Assessment and Epidemiology and the Division of Community Health Services in the Los Angeles County Department of Public Health for their contributions to the data collection of LA HANES. The authors also thank Janice Casil from the Division of Chronic Disease and Injury Prevention in the Public Health Department for her assistance with data analysis.

\section{REFERENCES}

1. United States Department of Agriculture and United States Department of Health and Human Services. Dietary Guidelines for Americans, 2010. 7th ed. Washington, DC: U.S. Government Printing Office (2010).

2. Ogden CL, Carroll MD, Kit BK, Flegal KM. Prevalence of childhood and adult obesity in the United States, 2011-2012. JAMA (2014) 311(8):806-14. doi:10.1001/jama.2014.732

3. Finkelstein EA, Trogdon JG, Cohen JW, Dietz W. Annual medical spending attributable to obesity: payer- and service-specific estimates. Health Aff (2009) 28(5):w822-31. doi:10.1377/hlthaff.28.5.w822

4. Story M, Kaphingst KM, Robinson-Obrien RR, Glanz K. Creating healthy food and eating environments: policy and environmental approaches. Annu Rev Public Health (2008) 29:253-72. doi:10.1146/annurev.publhealth.29.020907.090926

5. Glanz K, Sallis JF, Saelens BE, Lawrence DF. Healthy nutrition environments: concepts and measures. Am J Health Promot (2005) 19:5. doi:10.4278/0890$1171-19.5 .330$ 
6. United States Department of Agriculture. Access to Affordable and Nutritious Food-Measuring and Understanding Food Deserts and Their Consequences: Report to Congress. Washington, DC: United States Department of Agriculture (2009). Administrative Publication No. (AP-036).

7. Food Marketing Inst. Consumer Attitudes and the Supermarket. Washington, DC: Food Marketing Inst (2006).

8. Glanz K, Sallis JF, Saelens BE, Lawrence DF. Nutrition environment measures survey in stores (NEMS-S): development and evaluation. Am J Prev Med (2007) 32:282-9. doi:10.1016/j.amepre.2006.12.019

9. United States Department of Agriculture. How are Food Deserts Defined? (2013). Available from: http://apps.ams.usda.gov/fooddeserts/foodDeserts.aspx

10. Morland K, Wing S, Diez Roux A. The contextual effect of the local food environment on residents' diets: the atherosclerosis risk in communities study. Am J Public Health (2002) 92:11. doi:10.2105/AJPH.92.11.1761

11. Giskes K, Lenthe FV, Avendano-Pabon M, Brug J. A systematic review of environmental factors and obesogenic dietary intakes among adults: are we getting closer to understanding obesogenic environments? Obes Rev (2010) 12:e95-106. doi:10.1111/j.1467-789X.2010.00769.x

12. Hattori A, An R, Sturm R. Neighborhood food outlets, diet, and obesity among California adults, 2007 and 2009. Prev Chronic Dis (2013) 10:E35. doi: $10.5888 /$ pcd 10.120123

13. Budzynska K, West P, Savoy-Moore RT, Lindsey D, Winter M, Newby PK. A food desert in Detroit: associations with food shopping and eating behaviors, dietary intakes and obesity. Public Health Nutr (2013) 16:12. doi:10.1017/ S136898001300096

14. Bonnie G, Cohen D, Hunter G, Zenk SN, Huang C, Beckman R, et al. Distance to store, food prices, and obesity in urban food deserts. Am J Prev Med (2014) 47(5):587-95. doi:10.1016/j.amepre.2014.07.005

15. Li KY, Cromley EK, Fox AM, Horowitz CR. Evaluation of the placement of mobile fruit and vegetable vendors to alleviate food deserts in New York City. Prev Chronic Dis (2014) 11:E158. doi:10.5888/pcd11.140086

16. Wang MC, Kim S, Gonzalez AA, MacLeod KE, Winkleby MA. Socioeconomic and food-related physical characteristics of the neighbourhood environment are associated with body mass index. J Epidemiol Community Health (2007) 61(6):491-8. doi:10.1136/jech.2006.051680

17. National Cancer Institute. Fruit \& Vegetable Screeners in the Eating at America's Table Study (EATS): Scoring, 2013 (2013). Available from: http://appliedresearch. cancer.gov/diet/screeners/fruitveg/scoring/

18. Centers for Disease Control and Prevention. National Youth Physical Activity and Nutrition Study (NYPANS) (2013). Available from: http://www.cdc.gov/ healthyyouth/yrbs/nypans.htm

19. Stata Data Analysis Examples: Negative Binomial Regression. Los Angeles, CA: Institute for Digital Research and Education, University of California (2013). Available from: http://www.ats.ucla.edu/stat/stata/dae/nbreg.htm

20. Gustafson A, Christian JW, Lewis S, Moore K, Jilcott S. Food venue choice, consumer food environment, but not food venue availability within daily travel patterns are associated with dietary intake among adults, Lexington Kentucky 2011. Nutr J (2013) 12:17. doi:10.1186/1475-2891-12-17

21. D'Angelo H, Suratkar S, Song HJ, Stauffer E, Gittelsohn J. Access to food source and food source use are associated with healthy and unhealthy food-purchasing behaviors among low-income African-American adults in Baltimore City. Public Health Nutr (2011) 14:9. doi:10.1017/S1368980011000498
22. Inagami S, Cohen DA, Brown AF, Asch SM. Body mass index, neighborhood fast food and restaurant concentration, and car ownership. J Urban Health (2009) 86:5. doi:10.1007/s11524-009-9379-y

23. Fielding JE, Simon PA. Food deserts or food swamps? Arch Intern Med (2011) 171(13):1171-2. doi:10.1001/archinternmed.2011.279

24. Rose D, Bodor JN, Hutchinson PL, Swalm CM. The importance of a multidimensional approach for studying the links between food access and consumption. J Nutr (2010) 140:1170-4. doi:10.3945/jn.109.113159

25. Alwitt LF, Donley TD. Retail stores in poor urban neighborhoods. J Consum Aff (1997) 31:1. doi:10.1111/j.1745-6606.1997.tb00830.x

26. Short A, Guthman J, Raskin S. Food deserts, oases, or mirages? Small markets and community food security in the San Francisco Bay Area. J Plan Educ Res (2007) 26:352-64. doi:10.1177/0739456X06297795

27. California Center for Public Health Advocacy, PolicyLink, UCLA Center for Health Policy Research [CCPHA et al]. Designed for Disease: the Link Between Local Food Environments and Obesity and Diabetes. Los Angeles, CA: California Center for Public Health Advocacy, PolicyLink, UCLA Center for Health Policy Research [CCPHA et al] (2008).

28. Mari Gallagher Research and Consulting Group. Examining the Impact of Food Deserts on Public Health in Chicago. Chicago, IL: Mari Gallagher Research and Consulting Group (2006).

29. Mari Gallagher Research and Consulting Group. Examining the Impact of Food Deserts on Public Health in Detroit. Chicago, IL: Mari Gallagher Research and Consulting Group (2007).

30. Wrigley N, Warm D, Margetts B, Whelan A. Assessing the impact of improved retail access on diet in a 'food desert': a preliminary report. Urban Stud (2002) 39:11. doi:10.1080/0042098022000011362

31. Cummins S, Patticrew M, Higgins C, Findlay A, Sparks L. Large scale food retailing as an intervention for diet and health: quasi-experimental evaluation of a natural experiment. J Epidemiol Community Health (2005) 59:1035-40. doi:10.1136/jech.2004.029843

Conflict of Interest Statement: The authors report no conflicts of interest. The findings and conclusions in this article are those of the authors and do not necessarily represent the views or the official position of the Los Angeles County Department of Public Health.

Received: 25 September 2014; accepted: 25 October 2014; published online: 11 November 2014.

Citation: Gase LN, DeFosset AR, Smith LV and Kuo T (2014) The association between self-reported grocery store access, fruit and vegetable intake, sugar-sweetened beverage consumption, and obesity in a racially diverse, low-income population. Front. Public Health 2:229. doi: 10.3389/fpubh.2014.00229

This article was submitted to Epidemiology, a section of the journal Frontiers in Public Health.

Copyright (C) 2014 Gase, DeFosset, Smith and Kuo. This is an open-access article distributed under the terms of the Creative Commons Attribution License (CC BY). The use, distribution or reproduction in other forums is permitted, provided the original author(s) or licensor are credited and that the original publication in this journal is cited, in accordance with accepted academic practice. No use, distribution or reproduction is permitted which does not comply with these terms. 